\title{
Genome Sizes, Ploidy Levels, and Base Compositions of Styrax Species and Cultivars
}

\author{
Matthew S. Lobdell and Kimberly Shearer \\ The Morton Arboretum, 4100 Illinois Route 53, Lisle, IL 60532
}

Additional index words. chromosome number, cytology, flow cytometry, polyploidy, Styracaceae

\begin{abstract}
Styrax $\mathbf{L}$. is a genus of $\approx 130$ species, many with horticultural traits of interest, though sparsely represented in cultivation. Previous studies reporting chromosome counts have established a base chromosome number of $x=8$ and provided evidence of diploid, tetraploid, pentaploid, and hexaploid levels within the genus, including the more commonly cultivated Styrax japonicus Siebold \& Zucc. being reported as pentaploid. Little has been reported relative to genome size within the Styracaceae. We conducted flow cytometry using fluorochromes propidium iodide (PI) and 4',6-diamidino-2phenylindole (DAPI) to estimate relative $2 \mathrm{C}$ genome size and ploidy of 47 accessions representing 15 species of Styrax and base composition of a subset of 9 accessions representing 6 species. Cytologic analysis of chromosomes was completed on Styrax confusus Hemsl. for ploidy calibration to genome size. Diploids, tetraploids, pentaploids, hexaploids, and octoploids were identified. Relative $2 \mathrm{C}$ genome size ranged from 1.38 to 6.61 pg. This survey confirms published ploidy for Styrax americanus Lam., Styrax obassia Siebold \& Zucc., Styrax redivivus (Torr.) L.C.Wheeler (diploid), and S. japonicus (pentaploid); suggests alternate ploidy levels and/or ploidy series for Styrax grandifolius Aiton (diploid) and Styrax hookeri C.B.Clarke (octoploid); and establishes ploidy levels for Styrax glabrescens Benth., Styrax odoratissimus Champ. ex Benth., Styrax officinalis L., Styrax platanifolius Engelm. ex Torr., Styrax ramirezii Greenm., Styrax wilsonii Rehder (diploid), Styrax confusus, Styrax hemsleyanus Diels (tetraploid), and Styrax fortunei Hance (diploid and hexaploid).
\end{abstract}

Styrax is a genus consisting of $\approx 130$ species of both deciduous and evergreen woody trees and shrubs with a wide distribution spanning East and Southeast Asia, the Americas, and the Mediterranean. It is the largest genus of the Styracaceae, comprising $\approx 75 \%$ of the species in the family. Common diagnostic characteristics include leaves arranged alternately, flowers with corolla and calyx tubes each with five lobes or teeth, 10 epipetalous stamens, and a three-locular ovary (one-locular with age) with a single-stigma style (Lobdell, 2013).

Received for publication 7 Oct. 2021. Accepted for publication 8 Jan. 2021

Published online 11 February 2022.

We acknowledge Joe Rothleutner for his assistance with flow cytometry. Thanks to Pete Linsner and the Morton Arboretum Plant Production staff for greenhouse assistance. Thanks to Arboretum Wespelaar, JC Raulston Arboretum, The Morton Arboretum, Polly Hill Arboretum, University of California Botanical Garden at Berkeley, University of Delaware Botanic Gardens, and Will Overbeck for providing plant material used over the course of this study.

M.S.L. is Head of Collections and Curator, The Morton Arboretum.

K.S. is Manager of New Plant Development, The Morton Arboretum.

M.S.L. is the corresponding author. E-mail: mlobdell@mortonarb.org.

This is an open access article distributed under the CC BY-NC-ND license (https://creativecommons. org/licenses/by-nc-nd/4.0/).
Fritsch (1999) separates the genus into two sections. Section Styrax primarily contains the deciduous species of the genus found in North America, East Asia, and the Mediterranean; and section Valvatae Gürke contains the evergreen component distributed in East to Southeast Asia and South America. Section Styrax is divided into two series: Styrax and Cyrta (Lour.) P.W.Fritsch. Series Styrax contains species with entire margins and strictly terminal inflorescences, whereas series Cyrta contains those with glandulardenticulate to glandular-serrate margins and axillary in addition to terminal inflorescences. Series Cyrta accounts for $\approx 90 \%$ of section Styrax, as series Styrax consists only of three species with two found in the Southwestern United States and one in the Mediterranean. Section Valvatae is also divided into two series. Series Valvatae Perkins consists of the Neotropical plants with fruits containing a wet mesocarp and endocarp adherent to ellipsoid seeds possessing a non-crackled seedcoat; whereas series Benzoin Hayne (P.W. Fritsch) comprises the East and Southeast Asian species with a dry mesocarp and endocarp not adherent to the depressed-globose seeds with a crackled coat.

Styrax has been used since antiquity for the exudation of the balsamic resin produced by several species (Burkill, 1966; Langenheim, 2003; Pinyopusarerk, 1994; Zeybek, 1970). Today, Styrax are primarily cultivated for landscape use as ornamental flowering trees.
Flowers range from white to pink in color, campanulate to reflexed in shape, and although rather small in size (generally $1-2 \mathrm{~cm}$ ), they open in abundance in mid to late spring, persisting after common landscape trees such as Prunus L. and Magnolia L. have ceased flowering. J.C. Raulston of Raleigh, NC trialed the genus in the Southeastern United States (Raulston, 1992), sharing and promoting several uncommon species still represented in public gardens and private collections. Approximately 30 species are represented in global botanical gardens, although fewer than five species are common accessions (Lobdell, 2013).

$S$. japonicus and $S$. obassia are available in horticultural commerce. S. japonicus has become increasingly popular because of small size and extensive flowering (Dirr and Warren, 2019). Upwards of 30 cultivars have been named (Lobdell, 2013), with $\approx 10 \mathrm{com}$ monly available. Other East Asian Styrax species are rarely cultivated, little known, and confused in western horticulture due to phenotypic similarity. In European commerce, plants historically sold by Hillier Nurseries as Styrax dasyanthus var. cinerascens Rehder $(=S$. fortunei) were misidentified, instead representing $S$. confusus or Styrax serrulatus Roxb. (Grimshaw and Bayton, 2009). Styrax chinensis $\mathrm{Hu} \& \mathrm{~S}$. Ye Liang, S. grandiflorus Griff., Styrax huanus Rehder, and Styrax wuyuanensis S.M. Hwang are also frequently misapplied to cultivated plants in Western Europe (De Langhe, 2012). In addition, $S$. serrulatus has been misapplied to cultivated specimens of $S$. confusus in North America.

Due to the high variability of seedlings, chance seedling selections for novel traits have been relatively easy to introduce; however, a combination of traits, including pink flowering and burgundy foliage, tolerance of heat and humidity, and cold hardiness, are ornamental breeding objectives. Interspecific hybridization of Styrax has not been reported in the literature, neither from spontaneous sympatric species nor through controlled crosses. Hybridization is suspected in Styrax 'Wespelaar', a chance seedling of $S$. japonicus, with $S$. hemsleyanus as the putative pollen parent (Lobdell, 2013).

The base chromosome number for Styrax is $x=8$. Most species are reported as diploid $(2 n=2 x=16)$. Tetraploidy $(2 n=4 x=32)$ has been reported for $S$. grandifolius (Gonsoulin, 1974) and S. hookeri (Moore, 1973). Pentaploidy $(2 n=5 x=40)$ has been reported for S. japonicus (Baranec and Murin, 2003; Manshard, 1936). Diploid counts have also been reported for S. japonicus (Lobdell, 2013; Yamazaki, 1993), in addition to hexaploidy $(2 n=6 x=48)$ by Shiuchi and Fujita (2006). The only other species with multiple ploidy reports is $S$. hookeri, with a diploid count published (Mehra and Bawa, 1969) in addition to the previously mentioned tetraploid count. The only cultivar with reported ploidy is $S$. japonicus 'Pink Chimes', as diploid $(2 n=2 x=16)$ (Lobdell, 2013) (Table 1). Estimation of genome size across the genus has not been reported, and the vast majority 
Table 1. Summary of previously reported chromosome numbers and holoploid (2C) genome size measured in picograms (pg) for Styrax spp. investigated in this survey.

\begin{tabular}{lcl}
\hline Taxon & Previous reports & \multicolumn{1}{c}{ References } \\
\hline S. americanus & $2 n=2 x=16$ & Morawetz, 1991 \\
S. grandifolius & $2 n=4 x=32$ & Gonsoulin, 1974 \\
S. hookeri & $2 n=2 x=16$ & Mehra and Bawa, 1969 \\
& $2 n=4 x=32$ & Moore, 1973 \\
S. japonicus & $2 n=2 x=16$ & Lobdell, 2013; Yamazaki, 1993 \\
& $2 n=5 x=40$ & Baranec and Murin, 2003 \\
& $2 n=5 x+>40$ & Manshard, 1936 \\
S. obassia & $2 n=6 x=48$ & Shiuchi and Fujita, 2006 \\
S. officinalis & $2 n=2 x=16$ & Manshard, 1936 \\
S. redivivus & $1 \mathrm{C}=0.66 \mathrm{pg}$ & Bou Dagher-Kharrat et al., 2013 \\
\hline
\end{tabular}

of Styrax species lack chromosome counts or estimates of ploidy.

Polyploidy has played a significant role in the evolution of flowering plants, acting as a catalyst for diversification and speciation through the development of novel adaptations resulting from changes in gene function, expression, and epigenetics (Alix et al., 2017; Chen and Ni, 2006; Soltis and Burleigh, 2009; Soltis et al., 2009). Knowledge of existing polyploidy and genome size variation within a genus is essential for the development of breeding objectives and strategies. Variation in ploidy can be used in the development of cultivars with reduced fertility (Olsen et al., 2006; Phillips et al., 2016; Trueblood et al., 2010) and facilitate the success of wide hybrid crosses, and it can also be a barrier to successful hybridization if unknown (Johnston et al., 1980; Lafon-Placette et al., 2017).

Genome size is a taxonomically significant character that can vary both intraspecifically and intragenerically (Contreras and Shearer, 2018; Greilhuber, 1998; Ranney et al., 2007; Shearer and Ranney, 2013). Intraspecific variation can be due to reproductive isolation of populations, chromosomal variation, and heterochromatin polymorphisms (Greilhuber 1998). Intrageneric variation results from the ongoing processes of adaptation and evolution through which plants undergo whole genome duplication events and subsequent loss of genomic material (Bennetzen et al., 2005; Soltis et al., 2003). In addition to facilitating the effective development of breeding objectives and strategies, genome size data have been demonstrated as useful in clarifying taxonomy and nomenclature (Hembree et al., 2020; Ranney et al., 2007), screening interspecific hybrid seedlings (Galbraith et al., 2005; Parris et al., 2010; Shearer and Ranney, 2013), and determining ploidy (Contreras and Shearer, 2018; Lattier and Contreras, 2017; Roberts and Werner, 2016).

Genome size and ploidy can be measured relatively quickly through the use of flow cytometry, evident in the growing body of horticultural crop surveys (Contreras and Shearer, 2018; Hembree et al., 2020; Jones et al., 2007; Lattier and Contreras, 2017; Parris et al., 2010; Roberts and Werner, 2016; Rothleutner et al., 2016; Rounsaville and Ranney, 2010; Shearer and Ranney, 2013). The two most common fluorochromes for measuring genome size are PI and DAPI. PI is an intercalating stain that binds to the entire genome, making it necessary to digest samples with RNAse before measurement, whereas DAPI binds to AT-rich regions of the genome. Although PI provides more precision, DAPI is a more economical choice and does not require the additional step of enzyme digestion. In addition, through comparison of samples stained with different fluorochromes, it is possible to calculate base composition (Contreras and Shearer, 2018; Parris et al. 2010; Rothleutner et al., 2016). Doložel et al. (1992) reported the possibility of overestimating base composition when using base-specific fluorochromes such as DAPI. This issue can be overcome by identifying a more appropriate internal standard (a plant of known genome size used to calculate the genome size of a sample with unknown genome size) with comparable base composition. In more recent studies, base composition has been associated with climatic adaptations in plants, such as cold hardiness, drought tolerance (Šmarda et al., 2014), and dormancy (Trávníček et al., 2019).

The objectives of this study were to a) measure relative genome size and determine ploidy of a broad sampling of species and cultivars of Styrax, and b) determine the base composition of a subset of Styrax.

\section{Materials and Methods}

Taxonomy and determinations. Taxonomy selected for this study is according to Fritsch (1997, 2009), Huang et al. (2003), and Li and Fritsch (2018). When reproductive plant material was available, these references were also used to confirm determinations of specimens considered ambiguous. Accessions that could not be determined with a reasonable degree of certainty were removed from the study.

Flow cytometry. Relative 2C genome size of 47 accessions representing 15 species of Styrax was measured using flow cytometry. Wild collected and garden source material were obtained from public garden collections, including Arboretum Wespelaar (Haacht, Belgium), JC Raulston Arboretum (Raleigh, NC), The Morton Arboretum (Lisle, IL), The Polly Hill Arboretum (West Tisbury, MA), University of California Botanical Garden (Berkeley, CA), and University of Delaware Botanic Gardens (Newark, DE).
For each sample, $\approx 1 \mathrm{~cm}^{2}$ of young leaf tissue was cochopped with tender leaf tissue from the internal standard in $500 \mu \mathrm{L}$ of nuclei extraction buffer (Cystain PI Absolute P Nuclei Extraction Buffer; Sysmex Partec, Görlitz, Germany) using a sharp razor blade in a polystyrene petri dish. Extracted nuclei suspensions were filtered through 30- $\mu$ m nylon mesh filters (CellTrics; Partec, Franklin Park, IL) into sample tubes. For each accession, three samples were stained with $2 \mathrm{~mL}$ of PI solution and incubated with RNAse at $4{ }^{\circ} \mathrm{C}$ for at least $30 \mathrm{~min}$ (Cystain PI Absolute P; Sysmex Partec, Milan, Italy). For a subset of nine accessions representing six species, DAPI staining buffer (Cystain ultraviolet Precise P; Sysmex Partec) was used for base composition analysis. For each accession, three samples were prepared with the same chopping and filtering protocol as described previously using $400 \mu \mathrm{L}$ nuclei extraction buffer and $1.6 \mathrm{~mL}$ of DAPI staining buffer. For all sampled accessions, the internal standard Pisum sativum 'Ctirad' $(2 \mathrm{C}=8.76 \mathrm{pg})$ was used to calculate relative genome size (Bai et al., 2012; Greilhuber et al., 2007). Relative genome size (2C) was calculated using the following formula:

$$
\begin{aligned}
2 C= & \text { DNA content of standard } \\
& \times \frac{\text { Mean fluorescence value of sample }}{\text { Mean fluorescence value of standard }}
\end{aligned}
$$

and base pair (bp) composition was estimated with the following equation:

$$
\begin{aligned}
& \mathrm{AT} \%=\mathrm{AT} \% \text { standard } \\
& \times\left(\frac{\text { DAPI mean fluorescence standard } \div \text { DAPI mean fluorescence sample }}{\text { PI mean fluorescence standard } \div \text { PI mean fluorescence sample }}\right)^{1 / b}
\end{aligned}
$$

(Godelle et al., 1993), where $b$ represents binding length of DAPI (3.5 bp) and AT\% of $P$. sativum 'Ctirad' is 61.5 (Meister and Barow, 2007). Base pair composition was calculated as $\mathrm{GC} \%=100-\mathrm{AT} \%$. Relative genome size was measured on a flow cytometer (CyFlow Ploidy Analyzer, Sysmex) with fluorescence excitation of $365 \mathrm{~nm}$ for DAPI-stained samples and $532 \mathrm{~nm}$ for PI-stained samples.

Cytology. Cytology was used to verify the chromosome number and ploidy of $S$. confusus. Plants were grown in terra cotta pots in a glass house maintained at an average temperature of $\approx 22^{\circ} \mathrm{C}$. Actively growing root tips were collected following two sunny days before 1000 HR. Root tips were collected under relatively low light and suspended in prefixative solution of $2 \mathrm{~mm} 8$-hydroxyquinoline $+0.24 \mathrm{~mm}$ cycloheximide in glass vials and incubated on ice for $\approx 4 \mathrm{~h}$. Following prefixative treatment, root tips were rinsed three times using refrigerated deionized $\mathrm{H}_{2} \mathrm{O}$. Excess water was wicked away by placing root tips on a paper towel before suspension in Carnoy's solution ( 1 glacial acetic acid: 3 chloroform: 6 100\% EtOH). Root tips were incubated in fixative solution overnight for a minimum of $16 \mathrm{~h}$ at room temperature in the dark. On fixation, root tips were rinsed three times in deionized $\mathrm{H}_{2} \mathrm{O}$, placed in glass vials filled with $70 \%$ ethanol, and stored at $4{ }^{\circ} \mathrm{C}$ until needed. 


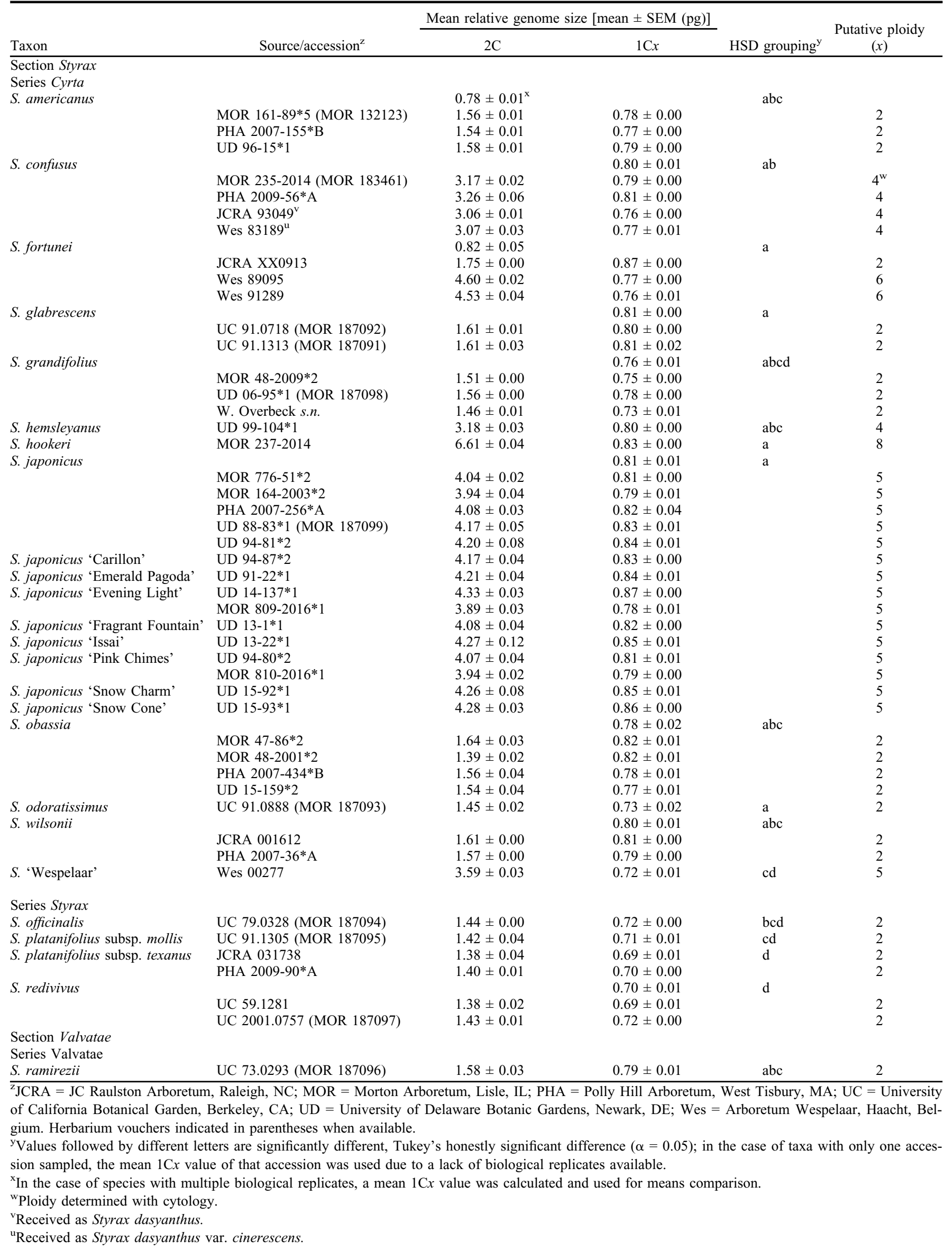


Root tip cell walls were broken down using enzyme digestion methods (Lattier et al., 2017). Optimal incubation time for $S$. confusus root tips was $\approx 4 \mathrm{~h}$. Following enzyme digestion, excised root apical meristematic tissue was stained with a single drop of modified carbol fuchsin stain (Kao, 1975). Using a razor blade bridge, a cover slip was placed over the root tip. Even application of pressure was applied to the coverslip and root tip using the short end of a Pentel Hi-Polymer block eraser. Prepared slides were screened on a light microscope (Axio Scope.A1; Zeiss, Thornwood, NY). Photomicrographs were captured using oil immersion at $\times 1000$ (AxioCam 503 color, Zeiss).

Statistical analyses. Analysis of variance was performed on monoploid genome sizes, and species means monoploid genome sizes were separated with Tukey's honestly significant difference, $\alpha=0.05$. Holoploid genome sizes of nine accessions in the fluorochrome treatment subset measured with both DAPI and PI were compared using a paired $t$ test, $\alpha=$ 0.05 . Statistical analyses were completed in RStudio (RStudio Team, 2020) with R software (R Core Team, 2020) and the package R/ agricolae (de Mendiburu and Yaseen, 2020).

\section{Results and Discussion}

Taxonomy and determinations. Nomenclatural corrections were applied, with accessions labeled Styrax calvescens Perkins and $S$. dasyanthus Perkins changed to $S$. fortunei. Two accessions of $S$. dasyanthus, Wes 83189 and JCRA 93049, were reclassified as $S$. confusus based on knowledge of origin. In the former case, the plant was purchased from Hillier Nurseries, representing a misapplication of the name $S$. dasyanthus var. cinerescens (Grimshaw and Bayton, 2009). In the latter case, the plant was received from the University of British Columbia Botanical Garden (UBCBG) with a source number of 28388-565-89 (M. Weathington, personal communication) Plants grown at UBCBG under the name $S$. dasyanthus during this time originated from a 1988 Sino-American Expedition to Huangshan, Anhui Province, China, and were later determined as $S$. confusus by Stephen A. Spongberg on the basis of racemose inflorescences consisting of five to eight flowers and fruits measuring $\approx 0.8$ to $1.0 \mathrm{~cm}$ diameter lacking pointed apices (D. Justice, E. La Fountaine, personal communication). Identification of MOR 235-2014 was changed from Styrax faberi to $S$. confusus following examination of flowering material due to absence of reddishbrown trichomes on the calyx.

Genome size and ploidy levels. Relative genome size and ploidy levels are reported in Table 2. Styrax confusus was the only species with countable root squashes, exhibiting a chromosome number of $2 n=4 x=32$ (Fig. 1), and was used to calibrate relative genome size to ploidy. Diploid, tetraploid, pentaploid, hexaploid, and octoploid levels were identified. Variability in ploidy level was confined to series Cyrta. Accessions representing series Styrax were measured as diploids. This survey

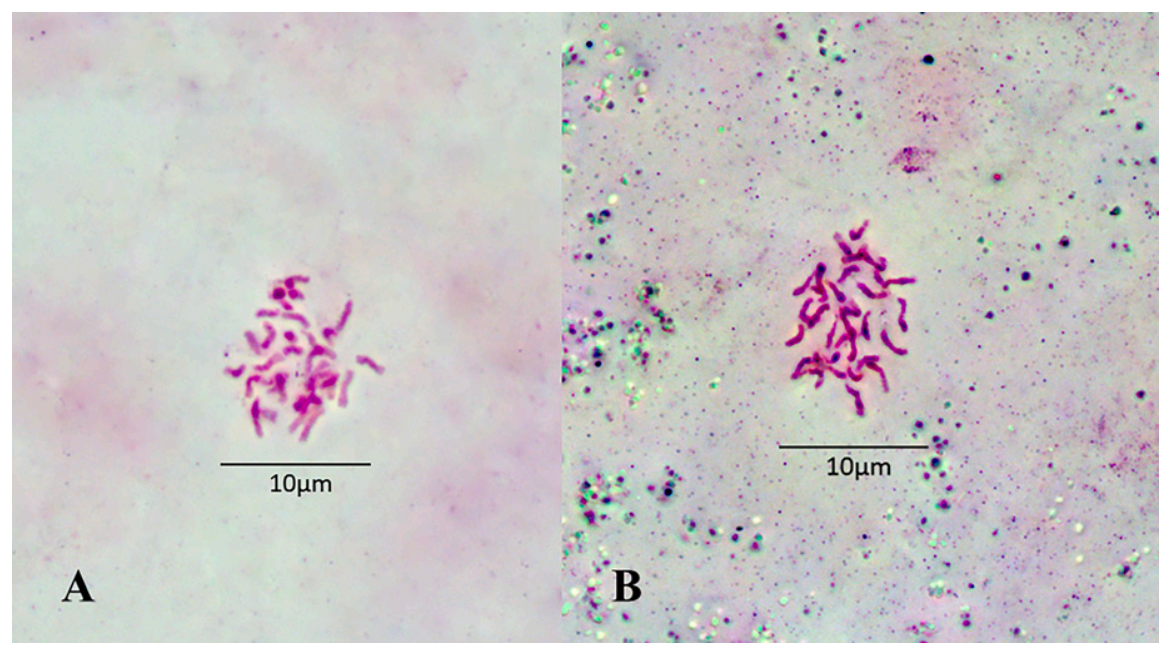

Fig. 1. Photomicrographs of root apical meristem cells from Styrax confusus MOR 235-2014 $(2 n=$ $4 x=40)(\mathbf{A}, \mathbf{B})$.

confirms the published count for S. redivivus (Copeland, 1938) and is the first to report a ploidy level for $S$. officinalis, as diploid. A diploid level is also established for S. platanifolius, based on the lower taxa $S$. platanifolius subsp. mollis P.W.Fritsch and S. platanifolius subsp. texanus (Cory) P.W.Fritsch. Additional taxa to evaluate in this taxonomic series include $S$. platanifolius var. platanifolius and S. platanifolius subsp. stellatus (Cory) P.W.Fritsch. Section Valvatae is rarely cultivated and little material was available for study. Styrax ramirezii, the only specimen of this section measured, was inferred to be a diploid.

All sampled accessions of $S$. americanus and $S$. grandifolius, temperate North American representatives of section Cyrta, were measured as diploids. This confirms the count published by Gonsoulin (1974) for $S$. americanus but contrasts with Gonsoulin's tetraploid report for $S$. grandifolius. Diploid accessions of $S$. grandifolius represent populations in Chesapeake City County, VA (MOR 48-2009*2); Lee County, KY ( $W$. Overbeck s.n.); and a plant from Woodlander's Nursery, Aiken, SC (UD 06-95*1), either originating from a local South Carolina population or a seed collection from extreme Southeastern Virginia (B. McCartney, personal communication). We have examined these accessions as living plants or representative herbarium samples and confirmed determination. Gonsoulin's (1974) tetraploid count is based on a collection in Lewis County, TN (Gonsoulin 1022), located $\approx 300 \mathrm{~km}$ southwest of the other collections. This suggests a ploidy series toward the western extent of the distribution; or that the Gonsoulin count was in error because of mistaking diploid cells for haploid cells during cytological preparation. Intraspecific ploidy variation associated with geographic distribution has been confirmed in Camellia reticulata (Wang and Ruan, 2012), Minuartia verna (Kabátova et al., 2019), and Seseli libanotis (Němečková et al., 2019). Further and more widespread sampling from across the distribution of $S$. grandifolius would be necessary to explore potential geographic intraspecific ploidy variation. This survey is the first to report ploidy level for $S$. glabrescens, S. odoratissi$m u s$, and $S$. wilsonii, and all three were determined to be diploid. The published diploid count for S. obassia (Manshard, 1936) is confirmed.

Tetraploidy is reported for two species without published chromosome counts: $S$. confusus and $S$. hemsleyanus. Although $S$. japonicus has been reported as diploid, pentaploid, and hexaploid, all accessions sampled for this survey were measured as pentaploids. Pentaploidy in S. japonicus has been reported in the literature (Baranec and Murin, 2003; Manshard, 1936); both diploid (Lobdell, 2013; Yamazaki, 1993) and hexaploid (Shiuchi and Fujita, 2006) cytotypes have been reported as well. It is possible that the pentaploids sampled in this survey are the progeny of hybridization events between the unreduced gamete of a diploid $(n=2)$ with the reduced gamete of a hexaploid $(n=3)$, and have been selected for cultivation through selection bias for pentaploids. Other natural and chance cytotypes of odd ploidy include individuals in Acer L. (pentaploids; Contreras and Shearer, 2018), Cotoneaster Medik. (triploids; Rothleutner et al., 2016), Magnolia (pentaploids; Parris et al., 2010), and Oxalis L. (pentaploids; Castro et al., 2007). All eight $S$. japonicus cultivars sampled appear to be pentaploid, suggesting that if numerous ploidy levels do exist across the species, then the pentaploid level is the most commonly cultivated.

Cytology of $S$. japonicus was difficult to determine, as the fine and brittle root tips were not readily digested by enzymes during cytological sample preparation. To overcome this issue, smaller samples of the root were taken; however, such samples were so small because of the fine nature of the roots that they dissolved completely in solution, and mitotic cells with condensed chromosomes could not be recovered from the sample. Refined protocol for cytology of $S$. japonicus could resolve this issue, and additional cytological work may clarify potential aneuploidy 
Table 3. Base pair composition of nine accessions representing six Styrax species calculated by comparing holoploid (2C) genome size measurements obtained through flow cytometric analysis of nuclei stained with $4^{\prime}$, 6-diamidino-2-phenylindole (DAPI) and propidium iodide (PI) using the internal standard Pisum sativum 'Ctirad'.

\begin{tabular}{|c|c|c|c|c|c|c|}
\hline \multirow[b]{2}{*}{ Taxon } & \multirow[b]{2}{*}{ Source/accession ${ }^{\mathrm{z}}$} & \multicolumn{2}{|c|}{$\begin{array}{l}\text { 2C genome size } \\
{[\text { mean } \pm \mathrm{SE}](\mathrm{pg})}\end{array}$} & \multirow[b]{2}{*}{ DAPI - PI } & \multirow[b]{2}{*}{$P$ value $^{\mathrm{y}}$} & \multirow[b]{2}{*}{$\mathrm{GC} \%{ }^{\mathrm{x}}$} \\
\hline & & DAPI & PI & & & \\
\hline$\overline{S . \text { americanus }}$ & MOR $161-89 * 5$ & $1.73 \pm 0.01$ & $1.56 \pm 0.01$ & 0.17 & 0.0001 & 40.24 \\
\hline S. confusus & MOR 235-2014 & $3.59 \pm 0.04$ & $3.17 \pm 0.02$ & 0.42 & 0.0007 & 40.64 \\
\hline S. hookeri & MOR 237-2014 & $7.60 \pm 0.03$ & $6.61 \pm 0.04$ & 0.99 & $<0.0001$ & 40.91 \\
\hline S. japonicus & MOR $164-2003 * 2$ & $4.74 \pm 0.07$ & $3.94 \pm 0.04$ & 0.80 & 0.0005 & 41.67 \\
\hline S. japonicus & MOR $776-51 * 2$ & $4.55 \pm 0.08$ & $4.04 \pm 0.02$ & 0.51 & 0.0037 & 40.57 \\
\hline S. japonicus 'Evening Light' & MOR 809-2016 & $4.66 \pm 0.17$ & $3.89 \pm 0.03$ & 0.77 & 0.0114 & 41.66 \\
\hline S. japonicus 'Pink Chimes' & MOR 810-2016 & $4.60 \pm 0.06$ & $3.94 \pm 0.02$ & 0.66 & 0.0004 & 41.19 \\
\hline S. odoratissimus & UC 91.0888 & $1.73 \pm 0.00$ & $1.45 \pm 0.02^{\mathrm{w}}$ & 0.28 & 0.0002 & 41.51 \\
\hline S. ramirezii & UC 73.0293 & $1.68 \pm 0.03$ & $1.58 \pm 0.03$ & 0.10 & 0.0539 & 39.47 \\
\hline
\end{tabular}

${ }^{\mathrm{z}} \mathrm{MOR}=$ Morton Arboretum, Lisle, IL; UC = University of California Botanical Garden, Berkeley, CA.

${ }^{\mathrm{y}} P$ value based on paired $t$ test comparing mean holoploid genome sizes determined using DAPI with PI, $\alpha=0.05$.

${ }^{\mathrm{x}} \mathrm{GC} \%=100-\{\mathrm{AT} \%$ for internal standard $\times[($ mean fluorescence standard DAPI/mean fluorescence sample DAPI $) /($ mean fluorescence standard PI/ mean fluorescence sample PI) $\left.]^{(1 / \text { binding length) }}\right\}$ (Godelle et al., 1993); AT\% of internal standard $=61.5$; binding length of DAPI = 3.5 bp (Meister and Barow, 2007).

${ }^{\mathrm{w}} n=2$.

or result in identifying a significantly different and distinct monoploid genome size within series Cyrta. Variability of monoploid genome size within a taxonomic group of a genus demonstrated in the big-bracted clade of Cornus L. (Shearer and Ranney, 2013).

$S$. hookeri was previously reported as a diploid (Mehra and Bawa, 1969) and tetraploid (Moore, 1973), whereas our results support an octoploid level for the species. It is uncertain whether these two earlier counts are in error, possibly from difficulties counting many small chromosomes, or if there is intraspecific ploidy variation in $S$. hookeri. It is also possible that the estimated monoploid genome size used to determine ploidy was not calibrated correctly for this species because of possible intergeneric differences in monoploid genome size, as has been demonstrated in maple (Contreras and Shearer, 2018) and dogwood (Shearer and Ranney, 2013).

$\mathrm{Li}$ and Fritsch (2018) subsumed both $S$. dasyanthus and $S$. calvescens into $S$. fortunei based on a lack of distinguishable characteristics. Our data suggest a ploidy series across this concept of $S$. fortunei. The accession received under the name $S$. calvescens is a diploid, representing a tree at JC Raulston Arboretum (xx0913) that is morphologically consistent with the botanical description in terms of leaf size and paired flowers in the leaf axils, but lacks the diagnostic leaf indumentum (Grimshaw and Bayton, 2009). Both accessions received under the name $S$. dasyanthus were measured as hexaploid. With diploid and hexaploid levels established within the $S$. fortunei complex, if sufficient geographic and phenological overlap is present across the distribution of this complex, the potential exists for tetraploid and other intermediate levels. A more thorough survey of material representing this complex, of both cultivated and wild origin, would be useful for better clarifying the extent of this variation.

One cultivar, $S$. Wespelaar, is a putative interspecific hybrid between the seed parent $S$. japonicus and the putative pollen parent $S$. hemsleyanus based on prominent reticulate leaf venation. Hybridization between these two species, a pentaploid $(n=2,3)$ and a tetraploid $(n=2)$, could result in either tetraploid (both gametes $n=2$ ), pentaploid ( $n=2$ and $n=3$ ), or aneuploid progeny. It is also possible that the $S$. japonicus parent was a hexaploid $(n=3)$, in which case the resulting hybrid would still be a pentaploid. It is also possible that the $S$. japonicus parent was a diploid $(n=1)$ and that the tetraploid parent (S. hemsleyanus) produced unreduced gametes $(n=4)$ resulting in pentaploid progeny; however, without any evidence supporting the production of unreduced gametes by $S$. hemsleyanus, the most likely scenario is that the $S$. japonicus parent was either a hexaploid or pentaploid. Our data best support $S$. 'Wespelaar' as a pentaploid. As demonstrated by Parris et al. (2010), hybrid progeny of pentaploids can exhibit highly variable genome size. A chromosome count will be necessary to accurately determine the chromosome number of this cultivar. In this case, monoploid genome size data do not provide any resolution relative to proposed parentage.

Base pair composition. A comparison of relative genome size measurements using the fluorochromes DAPI and PI and calculated bp compositions are presented in Table 3 . We found a significant difference relative to the fluorochrome used for measuring genome size across all taxa. Values determined using DAPI were consistently higher than those measured using PI with differences ranging from 0.10 to $0.99 \mathrm{pg}$. The consistent significant difference in mean relative genome size indicates that the taxa sampled in this study have a significantly different bp composition relative to the internal standard. In a 1992 fluorochrome study (Doložel et al.) comparing PI, DAPI, and mithramycin, the authors noted that factors contributing to differences in the estimation of genome size are significant differences in bp composition relative to the internal standard and differences in binding properties of the fluorochromes. Base pair composition of Styrax samples ranged from $39.47 \%$ to $41.67 \% \mathrm{GC}$, significantly different from the bp composition of the internal standard used (Pisum sativum 'Ctirad', 38.5\% GC). For more precise measurements of genome size in Styrax, PI should be used as a fluorochrome; however, DAPI is still a useful, efficient, and economic fluorochrome for the objective of determining ploidy once genome size to ploidy has been accurately calibrated.

\section{Conclusion}

Styrax presents opportunities for further horticultural evaluation, breeding, and introduction, although taxonomic confusion persists with some little-cultivated species, many represented by only a few enigmatic specimens in specialty collections. This survey provides new information regarding genome size, ploidy, and bp composition of Styrax, including the first ploidy reports for six species and a potential ploidy series in the $S$. fortunei complex. Further cytological work is needed to clarify ploidy variation in $S$. grandifolius, S. japonicus, and $S$. hookeri. In addition, this survey contributes to the growing census of genome sizes of angiosperms.

\section{Literature Cited}

Alix, K., P.R. Gérard, T. Schwarzacher, J.S. (Pat) Heslop-Harrison. 2017. Polyploidy and interspecific hybridization: Partners for adaptation, speciation and evolution in plants. Ann. Bot. 120: 183-194, https://doi.org/10.1093/aob/mcx079.

Bai, C., W.S. Alverson, A. Follansbee, and D.M. Waller. 2012. New reports of nuclear DNA content for 407 vascular plant taxa from the United States. Ann. Bot. 110:1623-1629, https://doi.org/ $10.1093 / \mathrm{aob} / \mathrm{mcs} 222$.

Baranec, T. and A. Murin. 2003. Karyological analyses of some Korean woody plants. Biologia 58:797-804.

Bennetzen, J.L., J. Ma, and K.M. Devos. 2005. Mechanisms of recent genome size variation in flowering plants. Ann. Bot. 95:127-132, https:// doi.org/10.1093/aob/mci008.

Bou Dagher-Kharrat, M., N. Abdel-Samad, B. Douaihy, M. Bourge, A. Fridlender, S. SiljakYakovlev, and S.C. Brown. 2013. Nuclear DNA 
C-values for biodiversity screening: Case of the Lebanese flora. Plant Biosyst. 147:1228-1237, https://doi.org/10.1080/11263504.2013.861530.

Burkill, I.H. 1966. A dictionary of the economic products of the Malay Peninsula, Vols. 1-2. Crown Agents for the Colony, London, England.

Castro, S., J. Loureiro, C. Santos, M. Ater, G. Ayensa, and L. Navarro. 2007. Distribution of flower morphs, ploidy level and sexual reproduction of the invasive weed Oxalis pes-caprae in the western area of the Mediterranean region. Ann. Bot. 99:510-517, https://doi.org/10.1093/aob/ $\mathrm{mcl} 273$.

Chen, Z.J. and Z. Ni. 2006. Mechanisms of genomic rearrangements and gene expression changes in plant polyploids. BioEssays 28:240-252, https:// doi.org/10.1002/bies.20374.

Contreras, R.N. and K. Shearer. 2018. Genome size, ploidy, and base composition of wild and cultivated Acer. J. Amer. Soc. Hort. Sci. 143:470-485, https://doi.org/10.21273/jashs04541-18.

Copeland, H.F. 1938. The Styrax of northern California and the relationships of the Styracaceae. Amer. J. Bot. 25:771-780, https://doi.org/ 10.1002/j.1537-2197.1938.tb12848.x.

De Langhe, J. 2012. Styracaceae: Vegetative key to species in cultivation. Ghent University Botanical Garden, Ghent.

De Mendiburu, F. and M. Yaseen. 2020. Agricolae: Statistical procedures for agricultural research. $\mathrm{R}$ package version 1.4.0, https://myaseen 208 . github.io/agricolae/https://cran.r-project.org/.

Dirr, M.A. and K. Warren. 2019. The tree book. Timber Press, Portland, OR.

Doložel, J., S. Sgorbati, and S. Lucretti. 1992. Comparison of three DNA fluorochromes for flow cytometric estimation of nuclear DNA content in plants. Physiol. Plant. 85:625-631, https://doi. org/10.1111/j.1399-3054.1992.tb04764.x.

Fritsch, P.W. 1997. A revision of Styrax (Styracaceae) for Western Texas, Mexico, and Mesoamerica. Ann. Mo. Bot. Gard. 84:705-761, https://doi.org/10.2307/2992026.

Fritsch, P.W. 1999. Phylogeny of Styrax based on morphological characters, with implications for biogeography and infrageneric classification. Syst. Bot. 24:356-378, https://doi.org/10.2307/ 2419695.

Fritsch, P.W. 2009. Styracaceae, p. 339-347. In: Flora of North America Editorial Committee (ed.). Flora of North America, vol. 8. Oxford University Press, Oxford, England.

Galbraith, D.W., J. Bartos, and J. Doložel. 2005. Flow cytometry and cell sorting in plant biotechnology, p. 291-322. In: L.A. Sklar (ed.). Flow cytometry in biotechnology. Oxford Univ. Press, New York, NY.

Godelle, B., D. Cartier, D. Marie, S.C. Brown, and S. Siljak-Yakovlev. 1993. Heterochromatin study demonstrating the non-linearity of fluorometry useful for calculating genomic base composition. Cytometry 14:618-626, https:// doi.org/10.1002/cyto.990140606.

Gonsoulin, G.J. 1974. A revision of Styrax (Styracaceae) in North America, Central America, and the Caribbean. SIDA 5:191-258, https:// www.jstor.org/stable/41966442.

Greilhuber, J. 1998. Intraspecific variation in genome size: A critical reassessment. Ann. Bot. 82(Suppl. 1):27-35, https://doi.org/10.1006/anbo. 1998.0725 .

Greilhuber, J., E.M. Temsch, and J.C.M. Loureiro. 2007. Nuclear DNA content measurement, p. 67-101. In: J. Doložel, J. Greilhuber, and J. Suda (eds.). Flow cytometry with plant cells: Analysis of genes, chromosomes and genomes. Wiley-VCH, Weinheim, Germany.
Grimshaw, J. and R. Bayton. 2009. New trees: Recent introductions to cultivation. Royal Botanic Gardens, Kew, London, England.

Huang, Y., P.W. Fritsch, and S. Shi. 2003. A revision of the imbricate group of Styrax series Cyrta (Styracaceae) in Asia. Ann. Mo. Bot. Gard. 90:491-553, https://doi.org/10.2307/3298541.

Hembree, W.G., T.G. Ranney, and N.P. Lynch. 2020. Identification, genome sizes, and ploidy of Deutzia. J. Amer. Soc. Hort. Sci. 145:88-94, https://doi.org/10.21273/JASHS04779-19.

Johnston, S.A., T.P.M. den Nijs, S.J. Peloquin, and R.E. Hanneman, Jr. 1980. The significance of genic balance to endosperm development in interspecific crosses. Theor. Appl. Genet. 57:5-9, https://doi.org/10.1007/BF00276002.

Jones, J.R., T.G. Ranney, and N.P. Lynch. 2007. Ploidy levels and relative genome sizes of diverse species, hybrids, and cultivars of Rhododendron. J. Amer. Rhododendr. Soc. 61:220-227.

Kabátova, K.N., F. Kolár, V. Jarolímová, K. Krak, and J. Chrtek. 2019. Does geography, evolutionary history or ecology drive ploidy and genome size variation in the Minuartia verna group (Caryophyllaceae) across Europe? Plant Syst. Evol. 305:1019-1040, https://doi.org/ 10.1007/s00606-019-01621-2.

Kao, K.N. 1975. A chromosomal staining method for cultured cells, p. 63-64. In: O.L. Gambourg and L.R. Wetter (eds.). Plant tissue culture methods. National Research Council of Canada, Saskatoon, Canada.

Lafon-Placette, C., I.M. Johannessen, K.S. Hornslien, M.F. Ali, K.N. Bjerkan, J. Bramsiepe, B.M. Glöckle, C.A. Rebernig, A.K. Brysting, P.E. Grini, and C. Köhler. 2017. Endosperm-based hybridization barriers explain the pattern of gene flow between Arabidopsis lyrata and Arabidopsis arenosa in central Europe. Proc. Natl. Acad. Sci. USA 114:E1027-E1035, https://doi.org/10.1073/ pnas. 1615123114.

Langenheim, J.H. 2003. Plant resins: Chemistry, evolution, and ethnobotany. Timber Press, Portland, OR.

Lattier, J.D., H. Chen, and R.N. Contreras. 2017. Improved method of enzyme digestion for root tip cytology. HortScience 52:1029-1032, https://doi.org/10.21273/HORTSCI12024-17.

Lattier, J.D. and R.N. Contreras. 2017. Ploidy and genome size in lilac species, cultivars, and interploid hybrids. J. Amer. Soc. Hort. Sci. 142:355366, https://doi.org/10.21273/JASHS04189-17.

Li, G. and P.W. Fritsch. 2018. A taxonomic revision of taxa in Styrax series Cyrta with valvate ccorollas. J. Bot. Res. Inst. Tex. 12:579-641, https://doi.org/10.2307/329854.

Lobdell, M.S. 2013. Styrax in cultivation: Evaluation of an underrepresented ornamental genus. Univ. of Delaware, Newark, MS Thesis, https://udspace.udel.edu/handle/19716/12870.

Manshard, E. 1936. Embryologische untersuchungen an Styrax obassia Sieb. Et Zucc. Planta 25:364 383, https://www.jstor.org/stable/23357204.

Mehra, P.N. and K.S. Bawa. 1969. Chromosomal evolution in tropical hardwoods. Evolution 23:466-481, https://doi.org/10.2307/2406701.

Meister, A. and M. Barow. 2007. DNA base composition of plant genomes, p. 177-213. In: J. Doložel, J. Greilhuber, and J. Suda (eds.). Flow cytometry with plant cells: Analysis of genes, chromosomes and genomes. Wiley-VCH, Weinheim, Germany.

Moore, R.J. 1973. Index to plant chromosome numbers for 1967-1971. Oosthoek's Uitgeversmaatschappij B.V., Utrecht, Netherlands.

Morawetz, W. 1991. The karyology of some neotropical Styracaceae. Plant Syst. Evol. 177:111-115, https://www.jstor.org/stable/23674667.
Němečková, H., K. Krak, and J. Chrtek. 2019. Complex pattern of ploidal and genetic variation in Seseli libanotis (Apiaceae). Ann. Bot. Fenn. 56:57-77, https://doi.org/10.5735/085.056.0111.

Olsen, R.T., T.G. Ranney, and D.J. Werner. 2006. Fertility and inheritance of variegated and purple foliage across a polyploid series in Hypericum androsaemum L. J. Amer. Soc. Hort. Sci. 131: 725-730, https://doi.org/10.21273/JASHS.131. 6.725 .

Parris, J.K., T.G. Ranney, H.T. Knap, and W.V. Baird. 2010. Ploidy levels, relative genome sizes, and base pair composition in Magnolia. J. Amer. Soc. Hort. Sci. 135:533-547, https:// doi.org/10.21273/JASHS.135.6.533.

Phillips, W.D., T.G. Ranney, D.H. Touchell, and T.A. Eaker. 2016. Fertility and reproductive pathways of triploid flowering pears (Pyrus sp.). HortScience 51:968-971, https://doi.org/ 10.21273/HORTSCI.51.8.968.

Pinyopusarerk, K. 1994. Styrax tonkinensis: Taxonomy, ecology, silvaculture and uses. ACIAR Technical Reports Series No. 31. ACIAR, Canberra.

Raulston, J.C. 1992. Styrax: A comprehensive review of a fascinating ornamental genus. Amer. Nurseryman 176(9):23-36.

Ranney, T.G., N.P. Lynch, P.R. Fantz, and P. Cappiello. 2007. Clarifying taxonomy and nomenclature of Fothergilla (Hamamelidaceae) cultivars and hybrids. HortScience 42:470-473, https://doi.org/10.21273/HORTSCI.42.3.470.

R Core Team. 2020. R: A language and environment for statistical computing. R Foundation for Statistical Computing, Vienna, Austria, https://www.R-project.org.

Roberts, D.J. and D.J. Werner. 2016. Genome size and ploidy levels of Cercis (redbud) species, cultivars, and botanical varieties. HortScience 51: 330-333, https://doi.org/10.21273/HORTSCI.51. 4.330 .

Rothleutner, J.J., M.W. Friddle, and R.N. Contreras. 2016. Ploidy levels, relative genome sizes, and base pair composition in Cotoneaster. J. Amer. Soc. Hort. Sci. 141:457-466, https://doi.org/10.21273/jashs03776-16.

Rounsaville, T.J. and T.G. Ranney. 2010. Ploidy levels and genome sizes of Berberis L. and Mahonia Nutt. species, hybrids, and cultivars. HortScience 45:1029-1033, https://doi.org/10.21273/HORT SCI.45.7.1029

RStudio Team. 2020. RStudio: Integrated development environment for R. RStudio, PBC, Boston, MA, http://www.rstudio.com.

Shearer, K. and T.G. Ranney. 2013. Ploidy levels and relative genome sizes of species, hybrids, and cultivars of dogwood (Cornus spp.). Hort Science 48:825-830, https://doi.org/10.21273/ HORTSCI.48.7.825.

Shiuchi, T. and T. Fujita. 2006. Chromosome number of Styrax japonicus Siebold et Zucc. var. tomentosus Hatushima (Styracaceae). Bull. Bot. Gard. Toyama 11:15-16.

Šmarda, P., P. Bureš, L. Horová, I.J. Leitch, L. Mucina, E. Pacini, L. Tichý, V. Grulich, and O. Rotreklová. 2014. Ecological and evolutionary significance of genomic GC content diversity in monocots. Proc. Natl. Acad. Sci. USA 111: E4096-E4102, https://doi.org/10.1073/pnas.132 1152111.

Soltis, D.E. and J.G. Burleigh. 2009. Surviving the K-T mass extinction: New perspectives of polyploidization in angiosperms. Proc. Natl. Acad. Sci. USA 106:5455-5456, https://doi. org/10.1073/pnas.0901994106.

Soltis, D.E., P.S. Soltis, M.D. Bennett, and I.J. Leitch. 2003. Evolution of genome size in the angiosperms. Amer. J. Bot. 90:1596-1603, https://doi.org/10.3732/ajb.90.11.1596. 
Soltis, D.E., V.A. Albert, J. Leebens-Mack, C.D Bell, A.H. Paterson, C. Zheng, D. Sankoff, C.W. dePamphilis, P.K. Wall, and P.S. Soltis. 2009. Polyploidy and angiosperm diversification. Amer. J. Bot. 96:336-348, https://doi.org/ 10.3732/ajb.0800079.

Trávníček, P., M. Čertner, J. Ponert, Z. Chumová, J. Jersáková, and J. Suda. 2019. Diversity in genome size and GC content shows adaptive potential in orchids and is closely linked to partial endoreplication, plant life-history traits and climatic conditions. New Phytol. 224:1642-1656, https://doi.org/ 10.1111/nph.15996.

Trueblood, C.E., T.G. Ranney, and N.P. Lynch. 2010. Evaluating fertility of triploid clones of Hypericum androsaemum L. for use as noninvasive landscape plants. HortScience 45: 1026-1028, https://doi.org/10.21273/HORTSCI. 45.7.1026.
Wang, B.-Y. and Z.-Y. Ruan. 2012. Genetic diversity and differentiation in Camellia reticulata (Theaceae) polyploid complex revealed by ISSR and ploidy. Genet. Mol. Res. 11:503-511, https://doi.org/10.4238/2012.March.6.3.

Yamazaki, T. 1993. Styracaceae, p. 104-116. In: Flora of Japan. Kodansha, Tokyo.

Zeybek, N. 1970. Liefert Styrax officinalis L. ein harz? Berichte der Schweizerischen Botanischen Gesellschaft 80:189-193. 